\title{
Regulatory effect of exogenous regucalcin on cell function in osteoblastic MC3T3-E1 cells: Involvement of intracellular signaling factor
}

\author{
YASUKO OTOMO and MASAYOSHI YAMAGUCHI \\ Laboratory of Endocrinology and Molecular Metabolism, Graduate School of Nutritional Sciences, \\ University of Shizuoka, 52-1 Yada, Suruga-ku, Shizuoka 422-8526, Japan
}

Received March 13, 2006; Accepted April 16, 2006

\begin{abstract}
Bone loss is induced in regucalcin transgenic rats. The role of exogenous regucalcin in the regulation of osteoblastic cell function was investigated. Osteoblastic MC3T3-E1 cells with subconfluent monolayers were cultured for $24-72 \mathrm{~h}$ in medium containing regucalcin $\left(10^{-10}\right.$ or $\left.10^{-9} \mathrm{M}\right)$ without fetal bovine serum. The presence of regucalcin did not have a significant effect on cell number. Culture with regucalcin $\left(10^{-9} \mathrm{M}\right)$ for $24 \mathrm{~h}$ caused a significant decrease in protein and DNA contents in osteoblastic cells. The effect of regucalcin in decreasing cellular protein content was significantly inhibited in the presence of various kinase inhibitors including staurosporine $\left(10^{-7} \mathrm{M}\right)$, dibucaine $\left(10^{-6} \mathrm{M}\right)$, PD98059 $\left(10^{-8} \mathrm{M}\right)$, or wortmannin $\left(10^{-8} \mathrm{M}\right)$. Meanwhile, culture with regucalcin caused a significant decrease in cellular DNA content in the presence of various kinase inhibitors. The presence of regucalcin did not have a significant effect on protein and DNA contents in the cells cultured with cycloheximide $\left(10^{-7} \mathrm{M}\right)$, an inhibitor of protein synthesis, or 5,6-dichloro -1- $\beta$-D-ribofuranosylbenzimidazole $\left(10^{-6} \mathrm{M}\right)$, an inhibitor of transcription activity; which each inhibitor caused a significant decrease in those contents. The effect of regucalcin in decreasing cellular protein content was seen in the presence of insulin-like growth factor-I (IGF-I; $10^{-9}$ or $10^{-8} \mathrm{M}$ ). Such an effect was not observed in cellular DNA content. The results of reverse transcription-polymerase chain reaction analysis with specific primers showed that the expression of Runx 2 (Cbfa 1) and alkaline phosphatase mRNAs in osteoblastic cells was significantly suppressed in the presence of regucalcin $\left(10^{-10}\right.$ or $\left.10^{-9} \mathrm{M}\right)$. Glyceraldhyde-3phosphate dehydrogenase mRNA level was not significantly
\end{abstract}

Correspondence to: $\operatorname{Dr} \mathrm{M}$. Yamaguchi, Laboratory of Endocrinology and Molecular Metabolism, Graduate School of Nutritional Sciences, University of Shizuoka, 52-1 Yada, Suruga-ku, Shizuoka 422-8526, Japan

E-mail address: yamaguch@u-shizuoka-ken.ac.jp

Key words: regucalcin, bone function, osteoblast changed with culture of regucalcin $\left(10^{-10}\right.$ or $\left.10^{-9} \mathrm{M}\right)$. This study supports the view that exogenous regucalcin regulates the function of osteoblastic cells, and that the effect of protein is mediated through signaling factors.

\section{Introduction}

Regucalcin was discovered in 1978 as a calcium-binding protein that does not contain EF-hand motif of $\mathrm{Ca}^{2+}$-binding domain (1-3). The name regucalcin was proposed for this $\mathrm{Ca}^{2+}$-binding protein, which may regulate $\mathrm{Ca}^{2+}$ and/or calmodulin effects on liver cell function $(4,5)$. In recent years, regucalcin has been demonstrated to play a multifunctional role in maintaining cell homeostasis and function as the regulatory protein in intracellular signaling process in many cell types (6-8).

Rat and human regucalcin genes are localized on chromosame X $(9,10)$. Regucalcin messenger ribonucleic acid (mRNA) and its protein are greatly present in liver and kidney cortex, and regucalcin is also found in other tissues $(11,12)$. The expression of regucalcin mRNA is mediated through the $\mathrm{Ca}^{2+}$-signaling mechanism $(13,14)$. AP1, NFI-A1 and RGPR-p117 (novel protein) have been found to be transcriptional factors for the enhancement of regucalcin gene promoter activity (15-17).

Regucalcin plays a role in maintaining intracellular $\mathrm{Ca}^{2+}$ homeostasis, the inhibitory regulation of various $\mathrm{Ca}^{2+}$ dependent protein kinases and tyrosine kinases, protein phosphatases, nitric oxide synthase, and the control of the enhancement of protein synthesis, nuclear deoxyribonucleic acid (DNA) and RNA synthesis in proliferative cells (6-8, 18-25). Recent study has demonstrated that regucalcin has suppressive effects on cell proliferation and apoptosis, which are mediated through many signaling factors, in cloned rat hepatoma H4-II-E cells and normal rat kidney proximal tubular epithelial NRK52E cells overexpressing regucalcin (26-28). Regucalcin has been proposed to play a role in maintaining cell homeostasis and function in many cell types (8).

We generated regucalcin transgenic (TG) rats to determine a regulatory role of endogenous regucalcin in vivo using a TG rat model (29). Bone loss and hyperlipidemia have been induced in regucalcin TG rats $(30,31)$, supporting the view that regucalcin has an important role on pathophysiologic state. 
The mechanism by which bone loss is induced in regucalcin TG rats has not been fully clarified. Regucalcin is expressed in rat bone marrow cells, and bone loss in regucalcin TG rats is partly involved in osteoclastic bone resorption $(32,33)$. Regucalcin has been demonstrated to stimulate osteoclast-like cell formation in mouse marrow culture in vitro, and the protein stimulates bone resorption in rat femoral tissue in vitro (34). Also, regucalcin is found to have suppressive effects on cell differentiation and mineralization in osteoblastic MC3T3-E1 cells in vitro $(35)$.

Furthermore, this study was undertaken to determine whether the effect of endogenous regucalcin on the function of osteoblastic cells in vitro is involved in intracellular signaling factors.

\section{Materials and methods}

Chemicals. $\alpha$-Minimal essential medium ( $\alpha$-MEM) and penicillin-streptomycin $(5000 \mathrm{U} / \mathrm{ml}$ penicillin: $5000 \mu \mathrm{g} / \mathrm{ml}$ streptomycin) were obtained from Gibco Laboratories. Fetal bovine serum (FBS) was obtained from Bioproducts INC. Staurosporine, PD98059, dibucaine, wartmannin, cycloheximide, 5,6-dichloro-1-ß-D-ribofuranosylbenzimidazole (DRB), and insulin-like growth factor-I (IGF-I) were obtained from Sigma Chemical Co. Other chemicals were of reagent grade and were obtained from Wako Pure Chemical Industries. All water used was glass distilled. Tissue culture plastic dishes were purchased from Falcon Plastics. Other materials used were commercial products of the highest grade available.

Isolation of regucalcin. Regucalcin is markedly expressed in the liver cytosol $(11,12)$. Regucalcin was isolated from rat liver cytosol. The livers were perfused with Tris- $\mathrm{HCl}$ buffer (pH 7.4, containing $100 \mathrm{mM}$ Tris, $120 \mathrm{mM} \mathrm{NaCl}, 4 \mathrm{mM} \mathrm{KCl}$, cooled to $4^{\circ} \mathrm{C}$ ). The livers were removed, cut into small pieces, and suspended 1:4 (weight:volume) in Tris- $\mathrm{HCl}$ buffer ( $\mathrm{pH} 7.4$ ); the homogenate was spun at 5,500 $\mathrm{x} \mathrm{g}$ in a refrigerated centrifuge for $10 \mathrm{~min}$, and the supernatant was spun at $105,000 \mathrm{x} \mathrm{g}$ for $60 \mathrm{~min}$. The resulting supernatant was heated at $60^{\circ} \mathrm{C}$ for $10 \mathrm{~min}$ and recentrifuged at $38,000 \mathrm{x} \mathrm{g}$ for $20 \mathrm{~min}$. Regucalcin in the supernatant was purified to electrophoretic homogeneity by gel filtration in Sephadex G-75 and G-50 followed by ion-exchange chromatography on diethylaminoethyl (DEAE)-cellulose, as reported previously (1).

Cell culture. Osteoclastic MC3T3-E1 cells were cultured at $37^{\circ} \mathrm{C}$ in a $\mathrm{CO}_{2}$ incubator in plastic dishes containing $\alpha$-MEM supplemented with $10 \%$ FBS. They were subcultured every 3 days using $0.2 \%$ trypsin plus $0.02 \%$ EDTA in $\mathrm{Ca}^{2+} / \mathrm{Mg}^{2+}$-free phosphate-buffered saline (PBS). For experiments, $\sim 1 \times 10^{5}$ cells per dish were cultured for 3 days to obtain subconfluent monolayers in $35-\mathrm{mm}$ plastic containing $2 \mathrm{ml} \alpha$-MEM with $10 \%$ FBS. After the cells were rinsed with FBS, the medium was exchanged for medium without FBS containing either vehicle or regucalcin $\left(10^{-10}\right.$ or $\left.10^{-9} \mathrm{M}\right)$ in the presence or absence of various inhibitors, and the cells were cultured further for 24-72 h. Cell viability was estimated by staining with trypan blue.
Cell counting. After trypsinization of the cells in each culture dish using a $\mathrm{Ca}^{2+} / \mathrm{Mg}^{2+}$-free PBS containing $0.2 \%$ trypsin and $0.02 \%$ EDTA for $2 \mathrm{~min}$ at $37^{\circ} \mathrm{C}$, cells were collected and wash-centrifuged in a PBS solution at $100 \mathrm{x}$ g for $5 \mathrm{~min}$. The cells were resuspended in a $0.5 \mathrm{ml}$ PBS solution, and an aliquot was stained with eosin. The cells were counted under a microscope using a hemocytometer plate. For each dish, we took the average of two counts.

Analytical procedures. To determine the protein concentration in osteoblastic cells, the cells were washed 3 times with PBS, scraped into $0.5 \mathrm{ml}$ of ice-cold $0.25 \mathrm{M}$ sucrose solution, and disrupted for $30 \mathrm{sec}$ with an ultrasonic device. Protein concentration in the cell homogenate was determined by the method of Lowry et al (36) and expressed as the amount of protein $(\mu \mathrm{g})$ per dish.

To measure DNA content in the cells, the cells were detached by using $0.2 \%$ trypsin plus $0.02 \%$ EDTA in $\mathrm{Ca}^{2+} / \mathrm{Mg}^{2+} /$ free PBS and washed with PBS. The cells were shaken with $2.0 \mathrm{ml}$ of ice-cold $0.1 \mathrm{~N} \mathrm{NaOH}$ solution for $6 \mathrm{~h}$ after disruption (37). After alkali extraction, the samples were centrifuged at $10,000 \mathrm{x}$ g for $5 \mathrm{~min}$, and the supernatant was determined by the method of Ceriotti (38) and expressed as the amount of DNA $(\mu \mathrm{g})$ per dish.

Determination of specific $m R N A$ by reverse transcriptionpolymerase chain reaction ( $R T-P C R)$. Total RNAs were prepared as described previously (39). Osteoblastic MC3T3-E1 cells with subconfluency were cultured for $24 \mathrm{~h}$ in medium containing either vehicle or regucalcin $\left(10^{-10}\right.$ or $\left.10^{-9} \mathrm{M}\right)$. After culture, cells were washed three times with ice-cold PBS, and then cells were homogenized in buffer solution containing $4 \mathrm{M}$ guanidinium thiocyanate, $24 \mathrm{mM}$ sodium citrate ( $\mathrm{pH} 7.0$ ), $0.5 \%$ sarcosyl, and isoamyl alcohol, and the phases were separated by centrifugation at $10,000 \mathrm{x} \mathrm{g}$ for $20 \mathrm{~min}$ at $4^{\circ} \mathrm{C}$. RNA located in the aqueous phase was precipitated with isoprepanol at $-20^{\circ} \mathrm{C}$. RNA precipitates were pelleted by centrifugation, and the pellets were redissolved in diethylpyrocarbonate-treated water.

RT-PCR was preformed with a Titam ${ }^{\text {TM }}$ one tube RTPCR kit (Roche Molecular Biochemicals) as recommended by the supplier. Primers for amplification of mouse Runx2 (type 1) cDNA were 5'-ATGCGTATTCCTGTAGA TCCGAG-3' (sense strand, positions 1016-1038 of cDNA sequence) and 5'-CATCATTCCCGGCCATGACGGTAAC-3' (antisense strand, positions 1451-1475) (40). The pair of oligonucleotide primers was designed to amplify a 459-bp sequence from the mRNA of mouse Runx2 (type 1). Primers for amplification of mouse alkaline phosphate cDMA were 5'-GATCGGGACTGGTACTCGGATAA-3' (sense strand, positions 729-751 of cDNA sequence) and 5'-CACATCA GTTCTGTTCTTCGGGTAC-3' (antisense strand, positions 860-884) (40). The pair of oligonucleotide primers was designed to amplify a 155-bp sequence from the mRNA of alkaline phosphatase. For semiquantitative PCR, glyceraldehyde-3-phosphate dehydrogenase (G3PDH) was used as an internal control to evaluate total RNA input. Primers for amplification of G3PDH cDNA were 5'-GATTTGGCCGT ATCGGACGC-3' (sense strand) and 5'-CTCCTTGGAGG CCATGTAGG-3' (antisense strand). The pair of oligo- 


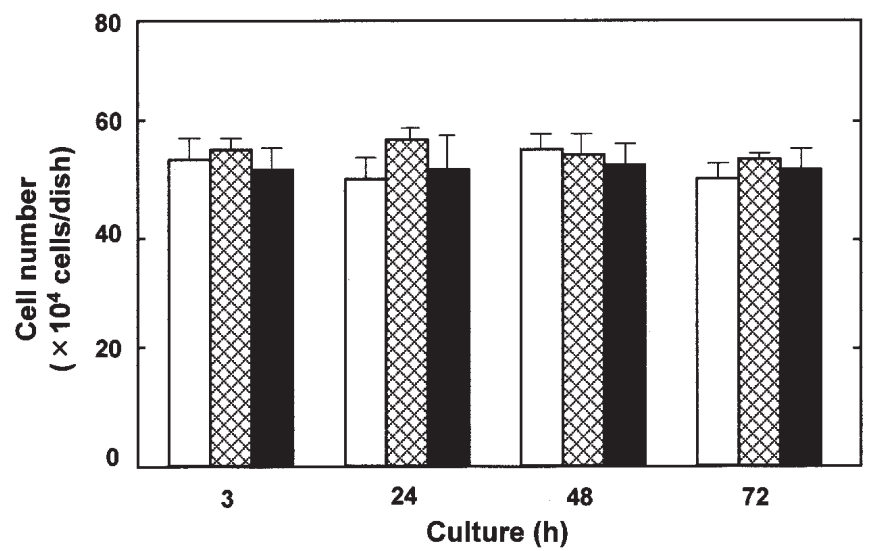

Figure 1. Effects of regucalcin on the number of osteoblastic MC3T3-E1 cells. Cells $\left(1 \times 10^{5}\right)$ were cultured for $72 \mathrm{~h}$ in medium containing $10 \%$ fetal bovine serum (FBS) to obtain subconfluent monolayers, and then in medium containing either vehicle or regucalcin $\left(10^{-10}\right.$ or $\left.10^{-9} \mathrm{M}\right)$ in the absence of $10 \%$ FBS. After medium change, cells were cultured for 3, 24, 48, or $72 \mathrm{~h}$. At each time point, the number of cells was measured. Each value is the mean \pm SEM of six experiments with separate cell culture. Data were not significant as compared with the control (none) value. White bars, control (none); double hatched bars, regucalcin $\left(10^{-10} \mathrm{M}\right)$; black bars, regucalcin $\left(10^{-9} \mathrm{M}\right)$.
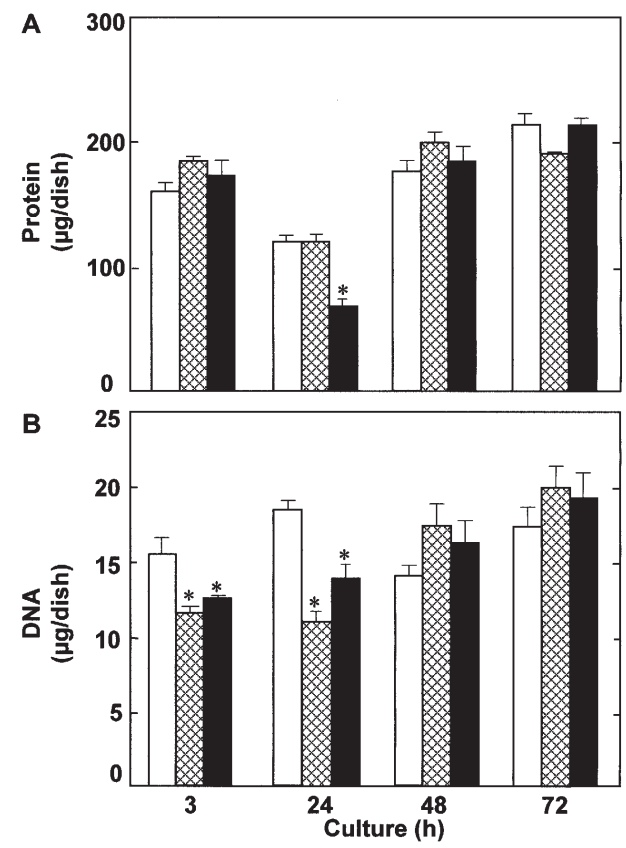

Figure 2. Effects of regucalcin on protein (A) and DNA (B) contents in osteoblastic MC3T3-E1 cells. Cells $\left(1 \times 10^{5}\right)$ were cultured for $72 \mathrm{~h}$ in medium containing $10 \%$ FBS. Cells with subconfluency were changed to medium containing either vehicle or regucalcin $\left(10^{-10}\right.$ or $\left.10^{-9} \mathrm{M}\right)$ in the absence of $10 \%$ FBS. At each time point, protein content in the cells was measured. Each value is the mean \pm SEM of six experiments with separate cell culture. ${ }^{*} \mathrm{P}<0.01$ compared with the control (none) value. White bars, control (none); double hatched bars, regucalcin $\left(10^{-10} \mathrm{M}\right)$; black bars, regucalcin $\left(10^{-9} \mathrm{M}\right)$

nucleotide primers was designed to amplify a 977-bp sequence from the mRNA of rat G3PDH. RT-PCR was performed using reaction mixture $(20 \mu \mathrm{l})$ containing 2 or $4 \mu \mathrm{g}$ of total RNA, supplied RT-TCR buffer, Titam ${ }^{\mathrm{TM}}$ enzyme mix (AMV and Expand $^{\mathrm{TM}}$ High Fidelity), $0.2 \mathrm{mM}$ dNTP, $5 \mathrm{mM}$ dithiothreitol,
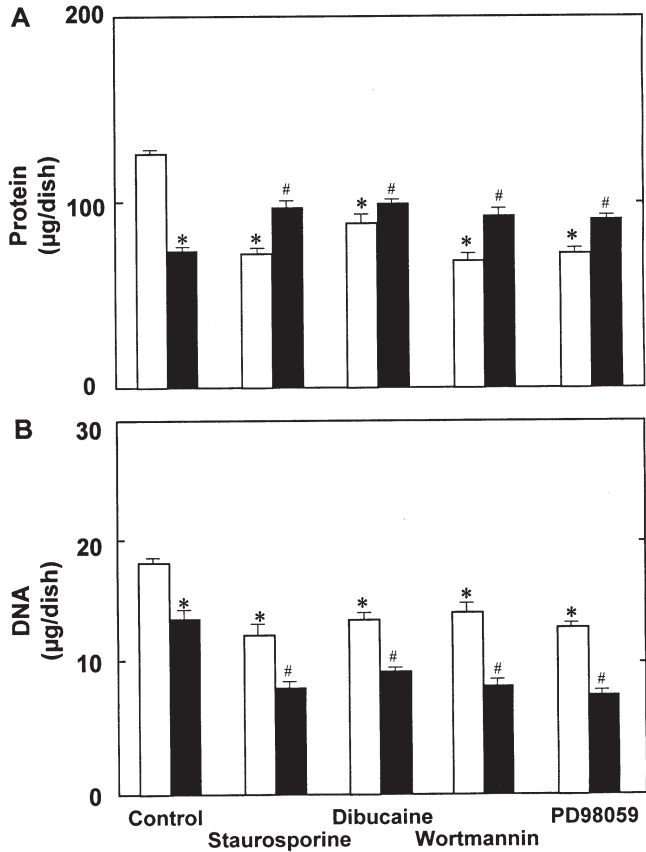

Figure 3. Effects of regucalcin on protein (A) and DNA (B) contents in osteoblastic MC3T3-E1 cells in the presence of signaling inhibitors. Cells $\left(1 \times 10^{5}\right)$ were cultured for $72 \mathrm{~h}$ in medium containing $10 \%$ FBS. Cells with subconfluency were cultured for $24 \mathrm{~h}$ in medium containing either vehicle or regucalcin $\left(10^{-9} \mathrm{M}\right)$ with or without staurosporine $\left(10^{-7} \mathrm{M}\right)$, dibucaine $\left(10^{-6} \mathrm{M}\right)$, worthmannin $\left(10^{-8} \mathrm{M}\right)$ or PD98059 $\left(10^{-8} \mathrm{M}\right)$ in the absence of $10 \%$ FBS. After culture, DNA content in the cell was measured. Each value is the mean \pm SEM of six experiments with separate cell culture. ${ }^{*} \mathrm{P}<0.01$ compared with the control (none) value. ${ }^{\#} \mathrm{P}<0.01$ compared with the value obtained from regucalcin alone. White bars, without regucalcin; black bars, with regucalcin.

$5 \mathrm{U}$ RNase inhibitor, and $0.3 \mu \mathrm{M}$ primers. Samples were incubated at $50^{\circ} \mathrm{C}$ for $30 \mathrm{~min}$, and then amplified for 30 cycles under the following conditions: denaturation for $30 \mathrm{sec}$ at $94^{\circ} \mathrm{C}$, annealing for $30 \mathrm{sec}$ at $56^{\circ} \mathrm{C}$, and extension for $60 \mathrm{sec}$ at $68^{\circ} \mathrm{C}$. The amplified products were separated by electrophoresis on a $1.5 \%$ agarose gel and visualized by ethidium bromide staining. Image density was quantified using a FluoroImager SI (Amersham Pharmacia Biotech).

Statistical analysis. Data are expressed as the mean \pm SEM. Statistical differences were analyzed using Student's t-test. P-values $<0.05$ were considered to indicate statistically significant differences. The ANOVA multiple comparison test was used to compare the treatment groups.

\section{Results}

Effects of regucalcin addition in osteoblastic MC3T3-E1 cells. Osteoblastic MC3T3-E1 cells were cultured for $72 \mathrm{~h}$ in medium containing $10 \%$ FBS. The cells with subconfluency were cultured for 24-72 $\mathrm{h}$ in medium containing either vehicle or regucalcin $\left(10^{-10}\right.$ or $\left.10^{-9} \mathrm{M}\right)$ without FBS. The number of cells was not significantly changed in the presence of regucalcin (Fig. 1). The presence of regucalcin $\left(10^{-9} \mathrm{M}\right)$ caused a significant decrease in protein content in the cells cultured for $24 \mathrm{~h}$ (Fig. 2A). DNA content in the cells was significantly decreased with culture of regucalcin 

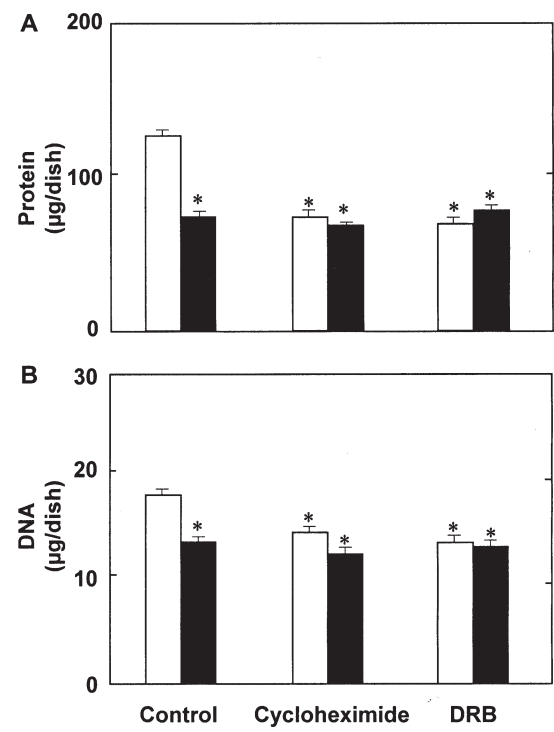

Figure 4. Effects of regucalcin on protein (A) and DNA (B) contents in osteoblastic MC3T3-E1 cells in the presence of cycloheximide or DRB. Cells $\left(1 \times 10^{5}\right)$ were cultured for $72 \mathrm{~h}$ in medium containing $10 \%$ FBS. Cells with subconfluency were cultured for $24 \mathrm{~h}$ in medium containing either vehicle or regucalcin $\left(10^{-9} \mathrm{M}\right)$ with or without cycloheximide $\left(10^{-7} \mathrm{M}\right)$ or DRB $\left(10^{-6} \mathrm{M}\right)$ in the absence of $10 \%$ FBS. After culture, protein content in the cells was measured. Each value is the mean \pm SEM of six experiments with separate cell culture. ${ }^{*} \mathrm{P}<0.01$ compared with the control (none) value. White bars, without regucalcin; black bars, with regucalcin.

$\left(10^{-10}\right.$ or $\left.10^{-9} \mathrm{M}\right)$ for 3 or $24 \mathrm{~h}$ (Fig. $\left.2 \mathrm{~B}\right)$. Thus, culture with regucalcin $\left(10^{-9} \mathrm{M}\right)$ caused a significant decrease in protein and DNA contents in osteoblastic MC3T3-E1 cells, indicating that extracellular regucalcin has a regulatory effect on cell function.

Effect of regucalcin in osteoblastic MC3T3-E1 cells in the presence of various inhibitors. Osteoblastic MC3T3-E1 cells with subconfluency were cultured for $24 \mathrm{~h}$ in a medium containing either vehicle or regucalcin $\left(10^{-9} \mathrm{M}\right)$ in the presence or absence of staurosporine $\left(10^{-7} \mathrm{M}\right)$, an inhibitor of protein kinase C (41), dibucaine $\left(10^{-6} \mathrm{M}\right)$, an inhibitor of $\mathrm{Ca}^{2+}$ calmodulin-dependent protein kinase (42), wortmannin $\left(10^{-8}\right.$ $\mathrm{M})$, an inhibitor of $\mathrm{PI}_{3}$ kinase (43), or PD $98059\left(10^{-8} \mathrm{M}\right)$, an inhibitor of mitogen-activated protein kinase (44) with an effective concentration (Fig. 3). The presence of staurosporine, dibucaine, wortmannin, or PD98059 caused a significant decrease in protein and DNA contents in osteoblastic MC3T3E1 cells. The effect of regucalcin in decreasing cellular protein content was significantly inhibited in the presence of staurosporine, dibucaine wortmannin, or PD98059 (Fig. 3A). The effect of regucalcin in decreasing cellular DNA content was also observed in the presence of staurosporine, dibucaine, wortmann, or PD98059 (Fig. 3B).

The effect of cycloheximide, an inhibitor of protein synthesis, or DRB, an inhibitor of transcription activity, on regucalcin action in osteoblastic MC3T3-E1 cells with subconfluency was examined (Fig. 4). Cells were cultured for $24 \mathrm{~h}$ in medium containing either vehicle or regucalcin $\left(10^{-9} \mathrm{M}\right)$ in the presence or absence of cycloheximide $\left(10^{-7} \mathrm{M}\right)$ or DRB $\left(10^{-6} \mathrm{M}\right)$. Cellular protein and DNA contents were significantly decreased with culture of cycloheximide or DRB. The
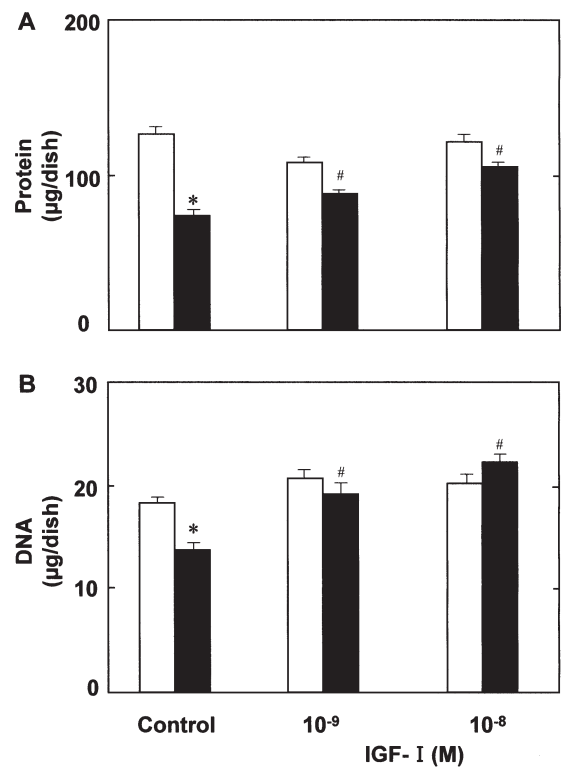

Figure 5. Effects of regucalcin on protein (A) and DNA (B) contents in osteoblastic MC3T3-E1 cells in the presence of IGF-I. Cells $\left(1 \times 10^{5}\right)$ were cultured for $72 \mathrm{~h}$ in medium containing $10 \%$ FBS. Cells with subconfluency were cultured for $24 \mathrm{~h}$ in medium containing either vehicle or regucalcin $\left(10^{-9} \mathrm{M}\right)$ with or without IGF-I $\left(10^{-9}\right.$ or $\left.10^{-8} \mathrm{M}\right)$ in the absence of $10 \%$ FBS. After culture, protein content in the cells was measured. Each value is the mean \pm SEM of six experiments with separate cell culture. ${ }^{*} \mathrm{P}<0.01$ compared with the control (none) value. White bars, without regucalcin; black bars, with regucalcin.

presence of regucalcin did not have a significant effect on protein and DNA contents in cells cultured with cycloheximide or DRB.

Effects of regucalcin in osteoblastic MC3T3-E1 cells in the presence of IGF-I. Osteoblastic MC3T3-E1 cells with subconfluency were cultured for $24 \mathrm{~h}$ in medium containing either vehicle or regucalcin $\left(10^{-9} \mathrm{M}\right)$ in the presence or absence of IGF-I $\left(10^{-9}\right.$ or $\left.10^{-8} \mathrm{M}\right)$. Culture with IGF-I did not have a significant effect on cellular protein and DNA contents (Fig. 5). The effect of regucalcin in decreasing cellular protein content was also seen in the presence of IGF$\mathrm{I}\left(10^{-9}\right.$ or $\left.10^{-8} \mathrm{M}\right)$ (Fig. 5A). However, the effect of regucalcin in decreasing cellular DNA content was not observed in the presence of IGF-I $\left(10^{-9}\right.$ or $\left.10^{-8} \mathrm{M}\right)$ (Fig. 5B).

Effect of regucalcin on gene expression in osteoblastic MC3T3E1 cells. Osteoblastic cells with subconfluency were cultured for $24 \mathrm{~h}$ in medium containing either vehicle or regucalcin $\left(10^{-10}\right.$ or $\left.10^{-9} \mathrm{M}\right)$ in the absence of FBS. The change in the expression of Runx2, alkaline phosphatase, or G3PDH mRNAs in osteoblastic cells was examined using RT-PCR analysis with specific primers (Fig. 6). The signal of bands for Runx 2 or alkaline phosphatase mRNA expression was significantly reduced in cells cultured in the presence of regucalcin $\left(10^{-10}\right.$ or $\left.10^{-9} \mathrm{M}\right)$. The levels of G3PDH mRNA were not significantly changed in the presence of regucalcin (Fig. 6C).

\section{Discussion}

Regucalcin is expressed in rat bone marrow cells and femoral tissue $(30,32)$. Bone loss is induced in regucalcin TG rats 
A Runx2
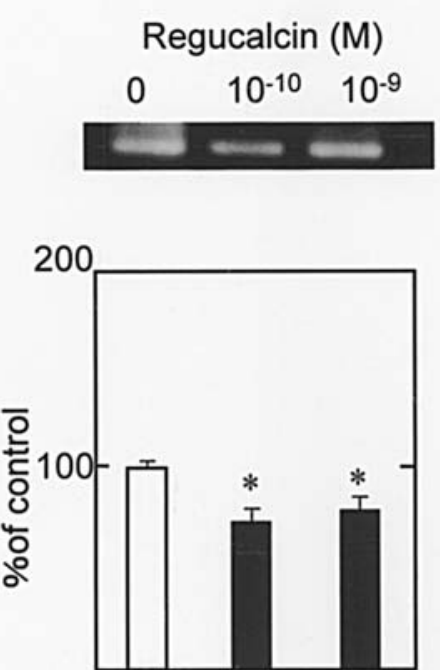

B Alkaline phosphatase
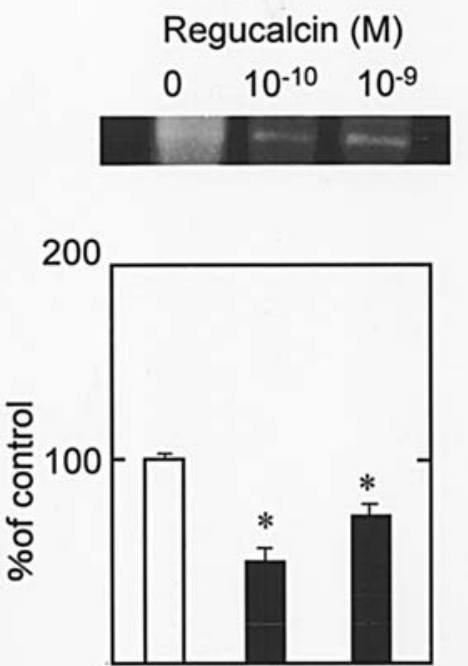

C G3PDH
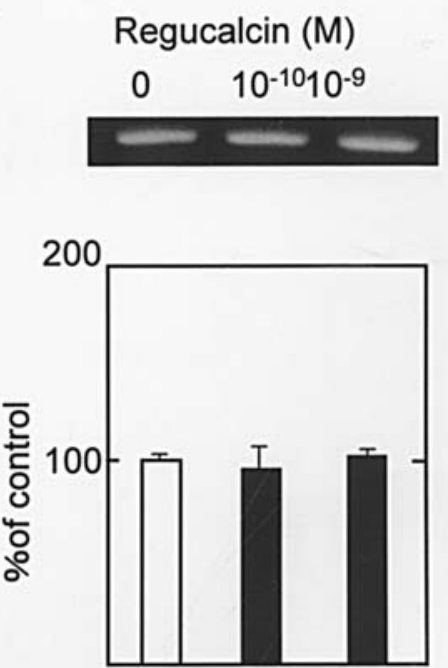

Figure 6. Effects of regucalcin on the expression of Runx2 (A), alkaline phosphtase (B) or G3PDH (C) mRNAs in osteoblastic MC3T3-E1 cells. Osteoblastic cells $\left(1 \times 10^{5}\right.$ cells) were cultured for $24 \mathrm{~h}$ in medium containing $10 \%$ FBS. Cells with subconfluency were changed to a medium without FBS in the presence or absence of regucalcin $\left(10^{-10}\right.$ or $\left.10^{-9} \mathrm{M}\right)$, and the cells were cultured for $24 \mathrm{~h}$. Total RNA ( $\left.2 \mu \mathrm{g}\right)$ extracted from the cells was analyzed by RT-PCR using specific primers. One of five experiments with separate samples. The densitometric data for each mRNA level in the cells cultured for $24 \mathrm{~h}$ in the presence of regucalcin were indicated as $\%$ of control (mean \pm SEM for five experiments). ${ }^{*} \mathrm{P}<0.01$ compared with the control value.

(30). The mechanism by which bone loss is induced in regucalcin TG rats has not been fully clarified. Bone loss in regucalcin TG rats is partly involved in osteoblastic bone resorption $(33,34)$. More recently, regucalcin has been shown to have suppressive effects on cell differentiation and mineralization in osteoblastic MC3T3-E1 cells that participate in bone formation and mineralization in vitro (35). Furthermore, this study has demonstrated that exogenous regucalcin has suppressive effects on protein and DNA contents in osteoblastic MC3T3-E1 cells in vitro.

The effect of regucalcin in decreasing protein and DNA contents in osteoblastic cells was observed at $24 \mathrm{~h}$ of culture with regucalcin addition. These decreases were restored at 48 and $72 \mathrm{~h}$. Regucalcin did not have a significant effect on cell number in osteoblastic cells with culture for $72 \mathrm{~h}$. It is speculated that exogenous regucalcin binds to the plasma membranes, and that the protein transmits signal(s) into osteoblastic cells. Iodinated regucalcin has been shown to bind to the plasma membranes isolated from rat liver in vitro (45). Specific binding sites for regucalcin in osteoblastic cells remain to be elucidated. Regucalcin may be released during longer culture times, and the protein signal may disappear in osteoblastic cells. This is in connection with the restoration of cellular protein and DNA contents reduced with culture of regucalcin.

The effect of regucalcin in decreasing protein contents in osteoblastic cells was inhibited in the presence of various kinase inhibitors including protein kinase $\mathrm{C}, \mathrm{Ca}^{2+}$ calmodulin-dependent protein kinase, PI3 kinase, and MAP kinase. This result suggests that the effect of regucalcin in decreasing cellular protein content is partly mediated through various protein kinases that are involved in intracellular signaling process. Meanwhile, culture with regucalcin caused a significant decrease in DNA content in osteoblastic cells in the presence of various kinase inhibitors. The effect of regucalcin in decreasing cellular DNA content may be involved in other signaling mechanisms, which differ from its action on cellular protein content. From these observations, it is assumed that the effect of exogenous regucalcin is mediated through several signaling pathways in osteoblastic cells.

The effects of regucalcin on protein and DNA contents in osteoblastic cells were examined in the presence of IGF-I, which can stimulate cell proliferation (46). The effect of regucalcin in decreasing cellular protein content was also seen in the presence of IGF-I. However, the regucalcin-induced decrease in cellular DNA content was not observed in the presence of IGF-I. Presumably, the effect of regucalcin is transmitted independent of the intracellular signaling process of IGF-I action.

Culture with regucalcin suppressed the expression of Runx2, a transcription factor (47), and alkaline phosphatase, a key enzyme of mineralization (48), mRNAs in osteoblastic cells. This result supports the view that endogenous regucalcin has suppressive effects on differentiation and mineralization in osteoblastic cells (35). In addition, the effect of regucalcin is transmitted to that transcription process in the nucleus of osteoblastic cells.

Culture with regucalcin may have inhibitory effects on protein and DNA syntheses, which are mediated through different intracellular signaling processes, in osteoblastic cells. At present, the signaling factors which are involved in regucalcin action are unknown. Various protein kinases may partly be related to the intracellular signaling of regucalcin action in osteoblastic cells. Moreover, other signaling factors may be involved in the action of regucalcin in osteoblastic cells. 
In conclusion, it has been demonstrated that exogenous regucalcin regulates the function of osteoblastic cells in vitro, and that regucalcin action is mediated through intracellular signaling factors.

\section{References}

1. Yamaguchi $\mathrm{M}$ and Yamamoto T: Purification of calcium binding substance from soluble fraction of normal rat liver. Chem Pharm Bull 26: 1915-1918, 1978.

2. Yamaguchi $M$ and Sugii K: Properties of calcium-binding protein isolated from the soluble fraction of normal rat liver. Chem Pharm Bull 29: 567-570, 1981 .

3. Shimokawa $\mathrm{N}$ and Yamaguchi M: Molecular cloning and sequencing of the cDNA coding for a calcium-binding protein regucalcin from rat liver. FEBS Lett 327: 251-255, 1993.

4. Yamaguchi $\mathrm{M}$ and Mori S: Effect of $\mathrm{Ca}^{2+}$ and $\mathrm{Zn}^{2+}$ on $5^{\prime}-$ nucleotidase activity in rat liver plasma membranes: hepatic calcium-binding protein (regucalcin) reverses the $\mathrm{Ca}^{2+}$ effect. Chem Pharm Bull 36: 321-325, 1988.

5. Yamaguchi $\mathrm{M}$ : A novel $\mathrm{Ca}^{2+}$-binding protein regucalcin and calcium inhibition. Regulatory role in liver cell function. In: Calcium Inhibition. Kohama K (ed). Japan Sci Soc Press Tokyo and CRC Press Boca Raton pp 19-41, 1992.

6. Yamaguchi M: Role of regucalcin in calcium signaling. Life Sci 66: 1769-1780, 2000.

7. Yamaguchi M: The role of regucalcin in nuclear regulation of regenerating liver. Biochem Biophys Res Commun 276: 1-6, 2000.

8. Yamaguchi $\mathrm{M}$ : Role of regucalcin in maintaining cell homeostasis and function (Review). Int J Mol Med 15: 371-389, 2005.

9. Shimokawa N, Matsuda Y and Yamaguchi M: Genomic cloning and chromosomal assignment of rat regucalcin gene. Mol Cell Biochem 151: 157-163, 1995.

10. Thiselton DL, McDowall J, Brandau O, Ramser J, d'Esposito F, Bhattacharga SS, Ross MT, Hardcastle AJ and Meindl A: An integrated, functionally annotated gene map of the DXS8026ELK1 internal on human Xp11.3-Xp11.23: potential hotspot for neurogenetic disorders. Genomics 79: 560-572, 2002.

11. Shimokawa $\mathrm{N}$ and Yamaguchi M: Calcium administration stimulates the expression of calcium-binding protein regucalcin mRNA in rat liver. FEBS Lett 305: 151-154, 1992.

12. Yamaguchi $\mathbf{M}$ and Isogai $\mathbf{M}$ : Tissue concentration of calciumbinding protein regucalcin in rats by enzyme-linked immunoadsorbent assay. Mol Cell Biochem 122: 65-68, 1993.

13. Murata T and Yamaguchi M: Promoter characterization of the rat gene for $\mathrm{Ca}^{2+}$-binding protein regucalcin. Transcriptional regulation by signaling factors. J Biol Chem 274: 1277-1285, 1999.

14. Nakajima M, Murata T and Yamaguchi M: Expression of calcium-binding protein regucalcin mRNA in the cloned rat hepatoma cells (H4-II-E) is stimulated through $\mathrm{Ca}^{2+}$ signaling factors: involvement of protein kinase C. Mol Cell Biochem 198: 101-107, 1999

15. Murata $\mathrm{T}$ and Yamaguchi $\mathrm{M}: \mathrm{Ca}^{2+}$ administration stimulates the binding of AP-1 factor to the 5'-flanking region of the rat gene for the $\mathrm{Ca}^{2+}$-binding protein regucalcin. Biochem J 329: 157-163, 1998.

16. Misawa $\mathrm{H}$ and Yamaguchi $\mathrm{M}$ : Indentification of transcription factor in the promoter region of rat regucalcin gene: binding of nuclear factor I-A1 to TTGGC motif. J Cell Biochem 84: 795-802, 2002.

17. Sawada N and Yamaguchi M: Overexpression of RGPR-p117 enhances regucalcin gene expression in cloned normal rat kidney proximal tubular epithelial cells. Int J Mol Med 16: 1049-1055, 2005.

18. Takahashi $\mathrm{H}$ and Yamaguchi $\mathrm{M}$ : Stimulatory effect of regucalcin on ATP-dependent calcium transport in rat liver plasma membranes. Mol Cell Biochem 168: 149-153, 1997.

19. Takahashi $\mathrm{H}$ and Yamaguchi $\mathrm{M}$ : Role of regucalcin as an activator of $\mathrm{Ca}^{2+}$-ATPase activity in rat liver plasma microsomes. J Cell Biochem 74: 663-669, 1999.

20. Katsumata T and Yamaguchi M: Inhibitory effect of calciumbinding protein regucalcin on protein kinase activity in the nuclei. J Cell Biochem 71: 569-576, 1998.

21. Omura M and Yamaguchi M: Regulation of protein phosphatase activity by regucalcin localization in rat liver nuclei. J Cell Biochem 75: 437-445, 1999.
22. Izumi T, Tsurusaki Y and Yamaguchi M: Suppressive effect of endogenous regucalcin on nitric oxide synthase activity in cloned rat hepatoma H4-II-E cells overexpressing regucalcin. J Cell Biochem 89: 800-807, 2003.

23. Tsurusaki Y and Yamaguchi M: Suppressive role of endogenous regucalcin in the enhancement of deoxyribonucleic acid synthesis activity in the nucleus of regenerating rat liver. J Cell Biochem 85: 516-522, 2002.

24. Tsurusaki Y and Yamaguchi M: Role of endogenous regucalcin in nuclear regulation of regenerating rat liver: suppression of the enhanced ribonucleic acid synthesis activity. J Cell Biochem 87: 450-457, 2002.

25. Tsurusaki Y and Yamaguchi M: Suppressive effect of endogenous regucalcin on the enhancement of protein synthesis and aminoacyl-tRNA synthetase activity in regenerating rat liver. Int $\mathbf{J}$ Mol Med 6: 295-299, 2000.

26. Misawa H, Inagaki S and Yamaguchi M: Suppression of cell proliferation and deoxyribonucleic acid synthesis in cloned rat hepatoma H4-II-E cells overexpressing regucalcin. J Cell Biochem 84: 143-149, 2002.

27. Nakagawa T, Sawada N and Yamaguchi M: Overexpression of regucalcin suppresses cell proliferation of cloned normal rat kidney proximal tubular epithelial NRK52E cells. Int J Mol Med 16: 637-643, 2005.

28. Izumi T and Yamaguchi M: Overexpression of regucalcin suppresses cell death and apoptosis in cloned rat hepatoma H4-IIE cells induced by lipopolysaccharide, PD98059, dubucaine, or Bay K 8644. J Cell Biochem 93: 598-608, 2004.

29. Yamaguchi M, Morooka Y, Misawa H, Tsurusaki Y and Nakajima R: Role of endogenous regucalcin in transgenic rats: suppression of kidney cortex cytosolic protein phosphatase activity and enhancement of heart muscle microsomal $\mathrm{Ca}^{2+}$-ATPase activity. J Cell Biochem 86: 520-529, 2002.

30. Yamaguchi M, Misawa Y, Uchiyama S, Morooka Y and Tsurusaki Y: Role of endogenous regucalcin in bone metabolism: bone loss is induced in regucalcin transgenic rats. Int $\mathrm{J}$ Mol Med 10: 377-383, 2002

31. Yamaguchi M, Igarashi A, Uchiyama S and Sawada N: Hyperlipidemia is induced in regucalcin transgenic rats with increasing age. Int J Mol Med 14: 647-651, 2004.

32. Yamaguchi M, Sawada N, Uchiyama S, Misawa H and Ma ZJ: Expression of regucalcin in rat bone marrow cells: involvement of osteoclastic bone resorption in regucalcin transgenic rat. Int $\mathrm{J}$ Mol Med 13: 437-443, 2004.

33. Uchiyama $\mathrm{S}$ and Yamaguchi $\mathrm{M}$ : Bone loss in regucalcin transgenic rats: Enhancement of osteoclastic cell formation from bone marrow of rats with increasing age. Int J Mol Med 14: 451455, 2004

34. Yamaguchi M and Uchiyama S: Regucalcin stimulates osteoclastlike cell formation in mouse marrow cultures. J Cell Biochem 94: 794-803, 2005

35. Yamaguchi M, Kobayashi M and Uchiyama S: Suppressive effect of regucalcin on cell differentiation and mineralization in osteoblastic MC3T3-E1 cells. J Cell Biochem 96: 543-554, 2005.

36. Lowry $\mathrm{OH}$, Rosebrough NJ, Farr AL and Randall RJ: Protein measurement with the Folin phenol reagent. J Biol Chem 193: 265-273, 1951.

37. Flanagan B and Nichols G Jr: Metabolic studies of bone in vitro IV. Collagen biosynthesis by surviving bone fragments in vitro. $\mathrm{J}$ Biol Chem 237: 3786-3792, 1962.

38. Ceriotti G: Determination of nucleic acids in animal tissues. J Biol Chem 241: 59-77, 1951.

39. Chomczyshi P and Sacchi N: Single-step method of RNA isolation by acid guanidium thiocyanate-phenol-chloroform extraction. Anal Biochem 162: 156-159, 1987.

40. Seth A, Lee BK, Qi S and Vary CPH: Coordinate expression of novel genes during osteoblast differentiation. J Bone Miner Res 15: 1683-1696, 2000.

41. Tamaoki T, Nomoto H, Takahashi I, Kato Y, Morimoto M and Tomita E: Staurosporin, a potent inhibitor of phospholipids/ $\mathrm{Ca}^{2+}$ dependent protein kinase. Biochem Biophys Res Commun 135: 397-402, 1986

42. Vincenzi FF: Pharmacology of calmodulin antagonism. In: Calcium Modulators. Godfraind T, Albertini A and Paoletti R (eds). Elsevier Biomedical Press Amsterdam, pp67-80, 1982.

43. Misawa $\mathrm{H}$ and Yamaguchi $\mathrm{M}$ : Intercellular signaling factorsenhanced hepatic nuclear protein binding to TTGGC sequence in the rat regucalcin gene promoter: Involvement of protein phosphorylation. Biochem Biophys Res Commun 279: 275-281, 2000. 
44. Zelivianshi S, Spellman M, Kollerman M, Kakitelashvilli V, Zhou XW, Lugo E, Lee MS, Taylor R, Davis TL, Hauke R and Lin MF: ERK inhibitor PD98059 enhances docetaxel-induced apoptosis of androgen-independent human prostate cancer cells. Int J Cancer 107: 478-485, 2003.

45. Yamaguchi M, Mori S and Kato S: Calcium-binding protein regucalcin is an activator of $\left(\mathrm{Ca}^{2+}-\mathrm{Mg}^{2+}\right)$-adenosine triphosphatase in the plasma membranes of rat liver. Chem Pharm Bull 36: 3532-3539, 1988.

46. Centrella M, McCarthy TL and Canalis E: Rceptors for insulinlike growth factors-I and -II in osteopblast-enriched cultures from fetal rat bone. Endocrinology 126: 39-44, 1990.
47. Stock M, Schafer H, Fliegauf M and Otto F: Identification of novel target of the bone-specific transcription factor Runx2. J Bone Miner Res 19: 959-972, 2004.

48. Yohay DA, Zhang J, Thrailkill KM, Arthur JM and Quarles LD: Role of serum in the developmental expression of alkaline phosphatase in MC3T3-E1 osteoblasts. J Cell Physiol 158: 467-475, 1994. 